\title{
Alkali and Hybrid-Alkali Flooding as a Tertiary Oil Recovery Mode: Prospects and Challenges
}

\author{
Nithin Chacko Thomas ${ }^{1}$, Bisweswar Ghosh ${ }^{2}$, Waleed S. AlAmeri ${ }^{3}$, Alibi Kilybay ${ }^{4}$ \\ ${ }^{1,2,3,4}$ The Petroleum Institute, Abu Dhabi, UAE
}

\begin{abstract}
Discovery of new oil being in declining trend and demand being on the rise, EOR technologies has to play a bigger role in the future to meet the energy demand and economics. This paper presents a comprehensive review of EOR technologies related to alkaline flooding and its hybrids. Alkaline flooding is one of the chemical enhanced oil recovery techniques in which high $\mathrm{pH}$ alkaline chemicals are injected to the reservoir for recovering the residual oil. It is among the oldest EOR techniques and its history started way back in the early $20^{\text {th }}$ century. The history of alkaline flooding, mechanisms by which it recovers oil, different process variations, the effectiveness and costs of different alkalis, problems associated with alkaline flooding and its application in carbonates are briefly reviewed in this paper. This paper also focuses on the reviews of the application of various hybrid floods developed along with alkali and their advantages, limitations both in clastic and carbonate reservoirs. The technical solutions to some of these challenges will be discussed.
\end{abstract}

\section{INTRODUCTION}

Alkaline flooding is an enhanced oil recovery technique in which an alkaline chemical such as sodium hydroxide, sodium orthosilicate or sodium carbonate is injected during polymer flooding or water flooding operations. The alkaline chemical reacts with certain types of oils, forming surfactants inside the reservoir. Eventually, the surfactants reduce the interfacial tension between oil and water and trigger an increase in oil production. Alkaline flooding is not recommended for carbonate reservoirs because of the abundance of calcium: the mixture between the alkaline chemical and the calcium ions can produce hydroxide precipitation that may damage the formation. Alkaline flooding is also known as caustic flooding". However, recent researches and field application has added more knowledge to this very important area of EOR there is much more to alkaline flooding than what has been described in the Schlumberger Oilfield Glossary. This article is an effort to update the reader with the past and recent development on Alkali for EOR application.

\section{History}

Alkali or caustic flooding is a process of enhanced oil recovery technique in which usually high $\mathrm{pH}$ alkaline solutions are injected into the reservoir. The injected alkaline chemicals react with the acidic component present in the crude oil and generate surfactants in-situ, which acts favorably for recovering the residual oil left after secondary oil recovery phase. Alkaline flooding is an established EOR technique which started in the early $20^{\text {th }}$ century. Squires F (1917) found that the oil displacement could be made more efficient by the introduction of an alkaline chemical into the flood water and also increasing the temperature of the water. This was the first ever published report which stated about the possibility of alkaline flooding for enhancing oil recovery. In the following years many laboratory investigations were conducted (Nutting, P.G. 1925-1928, cited by Johnson, C.R. 1976) which detailed the use of other alkaline chemicals like sodium silicate and sodium carbonate for increasing the recovery of oil by enhancing the performance of water flooding process. In 1927, Atkinson received the first patent right (in USA) for application of caustic/alkali for improving the oil recovery (Atkinson, 1927). Atkinson in his patent explained the advantages of using strong alkalis like hydroxides of potassium and sodium in increasing oil recovery from oil bearing sands. Many laboratory studies and field tests were conducted and reported in subsequent years, of which Beckstrom and Van Tuyl (1927) (cited by Johnson, C.R. 1976) is worth mentioning, who also advocated for use of strong alkalis like sodium carbonate, sodium hydroxide and potassium hydroxide. In 1942, another patent was issued for the use of sodium hydroxide, as an emulsifying agent that could be injected to the reservoir for improving oil recovery (Subkow, 1942). Being proved 
as a techno-economically effective EOR technique in many field trials, later works were focused on improving the efficiency of the alkaline flooding through hybridization. This led to the different process variations like Alkaline Polymer (AP), Alkaline Surfactant (AS) and Alkaline Surfactant Polymer (ASP) flooding. The application of alkaline flooding in the carbonates was not advisable in earlier times because of the precipitation and scaling problems. However, in the $21^{\text {st }}$ century, many researchers have started to find the use of alkaline flooding and its process variations in the carbonates in order to recover the residual oil.

\section{MeChanismS}

Many mechanisms for displacing the crude oil from the reservoirs are suggested in the literature for alkaline flooding. They are namely: emulsification and entrainment, emulsification and entrapment, wettability reversal (oil-wet to water-wet and also water-wet to oil-wet). These are the most commonly referred mechanisms (Johnson, C.R. 1976). In addition, there are other mechanisms like emulsification with coalescence, swelling of the oil phase and lowering of IFT as reported by deZabala et al., (1982) and better sweep emerging from altered flow by precipitates (Campbell,T.C. 1982). The following section provides a brief description of these mechanisms.

\subsection{Emulsification and Entrainment}

Most crude oil contains sizable amount of mono and polycyclic acids, called naphthenic acids which react with alkalis at different kinetic rate to create surfactants or emulsifiers in-situ. Emulsification is the outcome of lowering oil-water IFT, the results of generation of surfactants in-situ upon the reaction between the injected alkali and the naphthenic acids present in the crude oil. The in-situ emulsification results in entraining the oil in water and allows it flow through the reservoir pores and produce along with water. This mechanism was first reported by Subkow in 1942. A patent for oil production from tar sands was awarded in 1966, which proposed a mechanism in which tar sands were initially fractured and alkali was injected later. The injected alkaline solution created emulsions in-situ and the oil could be produced by injecting steam to heat the oil and pushing the produced emulsion towards the production well. The fundamental mechanism for oil recovery as per this patent was emulsification and entrainment (Doscher, T.M. 1956).

\subsection{Emulsification and Entrapment}

Emulsification and entrapment is another mechanism suggested by Jennings et al., (1974), in which an emulsion blob of appropriate size will plug the pore throats. This will seal off high permeability channels and provide better mobility control between the displacing and displaced fluids, thus reducing the chances of viscous fingering and eventually improving volumetric sweep efficiency. In this mechanism, the emulsion generated is entrapped in the pore throat. Hence, the incremental oil recovered can be attributed to the resultant of improved volumetric sweeping attained.

\subsection{Wettability Reversal (Oil-Wet To Water-Wet)}

Injection of alkaline chemicals can create the wettability alteration on the rock surface from oil-wet to more water-wet state. And since the wettability is changed towards more water-wet sate, the residual oil remaining in the pore spaces and the dislodged oil form the rock surfaces can be easily be produced. Laboratory experiments conducted by Wagner et al., 1959 confirmed this mechanism of improved oil recovery by injecting the water solutions carrying different chemicals (acids and bases). However, acids cannot be used in the field due to the adverse problems it can create upon reaction with the reservoir rock. Sodium hydroxide $(\mathrm{NaOH})$ was the base used as the chemical for altering the wettability in the laboratory test (Wagner et al., 1959). Leach et al., (1962), confirmed improved oil recovery by wettability reversal from oil-wet to water-wet condition. Tests were conducted on Berea core plugs in the laboratory by using oil and water from the real field for contact angle measurements to confirm the wettability reversal process. Sodium hydroxide alkali was used as the chemical for injection and it changed the Berea core's wettability from oil-wet to water wet. $\mathrm{NaOH}$ alkali being found successful as a wettability reversal agent in the laboratory was later used in the field trial in Harrisburg Muddy "J" reservoir, Nebraska. The field trial was successful and incremental recovery of the residual oil was observed and it confirmed wettability reversal that took place in the reservoir using alkaline chemical (Leach et al., 1962). Laboratory works using polytetrafluoroethylene cores reiterated the beneficial side of wettability change from oil-wet to water-wet for improving oil recovery (Mungan.N, 1966). 


\subsection{Wettability Reversal (Water-Wet To Oil-Wet)}

This is another mechanism for improved oil recovery by alkaline flooding proposed by Cooke et al., (1974). According to them the surfactants generated in-situwill reduce the IFT between the crude oil and the water phase of the flooded water to a great extent and the wettability of the rock surface would be changed to oil-wet state under the appropriate conditions of salinity, temperature and $\mathrm{pH}$. The IFT reduction will create ahigh viscous oil in water emulsion which would produce a pressure gradient that is not uniform across the small region near to the emulsion front. This pressure gradient must be large enough to overcome the reduced capillary forces in the pore space and dislodge the oil (Cooke et al., 1974).

All the above mentioned mechanisms may not be present or active during all alkaline flooding and one or more mechanism may be active during a particular alkaline flooding process. Among the different stated mechanisms, the IFT reduction is most important and primary mechanism for oil displacement (Surkalo, 1990). The reduction of IFT is associated with the surfactants generated in-situ by the chemical reactions between the alkalis being injected and the acid groups present in the crude oil.

The surfactants generation in-situ reaction equation is given below and schematic in Figure: 1

$\mathrm{HA}+\mathrm{OH}^{-} \rightarrow \mathrm{A}^{-}+\mathrm{H}_{2} \mathrm{O}$

In the above equation, $\mathrm{HA}$ is the pseudo-acid component and $\mathrm{A}^{-}$is the soap or surfactant generated.

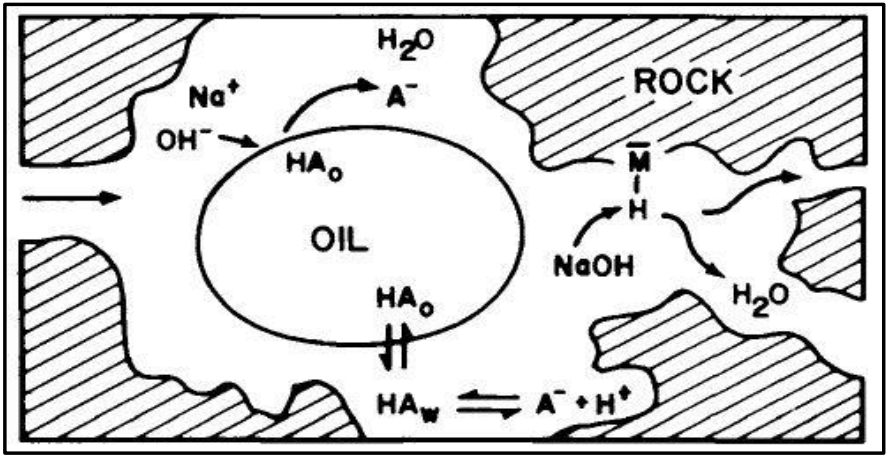

Figure1. Schematic of in-situ surfactant generation (deZabala, et al., 1982)

Since the surfactant generation is directly linked to the acids in the crude oil, alkaline flooding is considered to be effective in reservoirs having high acid number crudes. Another laboratory studies with sandstone core and $\mathrm{NaOH}$ as alkali, found that the wettability alteration towards more water-wet state and IFT reduction are the main mechanisms for incremental oil recovery by alkaline flooding (Ehrlich et al., 1974).

\section{Comparison of DifFerent AlKalis}

Many different types of alkaline chemicals have been evaluated and applied in various alkaline

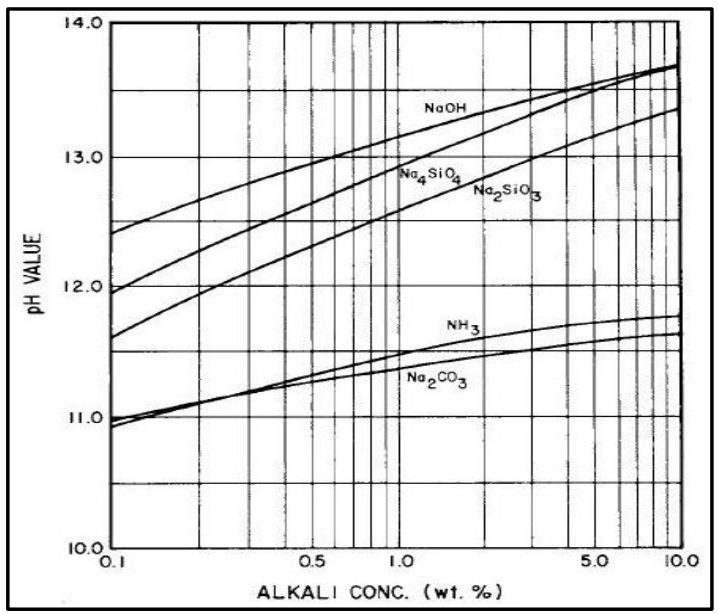

Figure2. The pH comparison of various commonly used alkaline chemicals with variation in the concentration (Mayer et al., 1983) 
Flooding projects. The most widely used alkalis are sodium hydroxide $(\mathrm{NaOH})$, sodium carbonate $\left(\mathrm{Na}_{2} \mathrm{CO}_{3}\right)$, sodium orthosilicate $\left(\mathrm{Na}_{4} \mathrm{SiO}_{4}\right)$, sodium metasilicate $\left(\mathrm{Na}_{2} \mathrm{SiO}_{3}\right)$ and ammonia $\left(\mathrm{NH}_{3}\right)$. The $\mathrm{pH}$ value of the alkaline buffers made from these alkalis will vary in accordance with the concentration of alkalis added in the solution. A comparison of the $\mathrm{pH}$ value with the variation in alkaline concentration of different alkalis was reported and is given in Figure: 2. It is clear from the figure that $\mathrm{NaOH}$ is the strongest among the given alkalis and $\mathrm{Na}_{2} \mathrm{CO}_{3}$ the weakest.

Cheng (1986) reported that, consumption of alkaline chemicals during alkaline flooding can be considerably reduced by using sodium carbonate and the breakthrough times of the alkali will be minimized. Studies conducted on Ottawa sand, Wilmington sand and dolomite using different alkalis revealed that sodium carbonate showed considerably lower mineral dissolution and ion exchange when compared with sodium hydroxide and sodium orthosilicate. Cheng (1986), also reported that carbonate precipitates do not unfavorably affect permeability due to its relatively smaller size when compared to the precipitates of the silicates or the hydroxides (Cheng K.H, 1986). Another laboratory study has been conducted for comparing the corrosive nature of different alkaline solutions on sandstone cores. $\mathrm{Na}_{2} \mathrm{CO}_{3}$ has been proved to be least corrosive when compared to $\mathrm{NaOH}$ and $\mathrm{Na}_{4} \mathrm{SiO}_{4}$. $\mathrm{Na}_{2} \mathrm{CO}_{3}$ buffering action can minimize the retention of alkalis on the rock surface (Burk J.H., 1987).

PQ Corporation in 2006 released a bulletin in which comparison of the effectiveness of different alkaline chemicals in EOR application is reported. Sodium orthosilicate was reported to be the most cost efficient since it can yield an increased level of performance which can make the alkaline flooding more economical (PQ Corporation, 2006). The comparison of EOR potential of different alkalis is given in Table 1.

Table1. Comparison of EOR potential of different alkalis (PQ Corporation, 2006)

\begin{tabular}{|c|c|c|c|}
\hline Property & Sodium Hydroxide & Sodium Carbonate & Sodium Orthosilicate \\
\hline Formula & $\mathrm{NaOH}$ & $\mathrm{Na} 2 \mathrm{CO} 3$ & $\mathrm{Na} 4 \mathrm{SiO} 4$ \\
\hline Equivalent Na2O & 1.0 & 1.32 & 1.15 \\
\hline $\mathrm{pH}(1.0 \%$ solution) & 13.15 & 11.37 & 12.92 \\
\hline Hardness & ppt. Ca2+, $\mathrm{Mg} 2+$ & $\mathrm{ppt.} \mathrm{Ca} 2+$ & $\mathrm{ppt}$ Ca2+, Mg $2+$ \\
\hline Residual in solution & $(30-50 \mathrm{ppm})$ & Fair & Best \\
\hline IFT (hard water) & Good & Least & Bederate \\
\hline Consumption & High & Fair & Best \\
\hline $\begin{array}{c}\text { Surfactant absorption } \\
\text { minimized }\end{array}$ & Poor & Unknown & Best \\
\hline Water wetness & Fair & Fair & Best (1.0) \\
\hline Sweep improvement & Fair & Fair $(0.65)$ & \\
\hline Recovery & Good $(0.8)$ &
\end{tabular}

\section{High Alkali Consumption Problem due to Precipitation, Dissolution and Ion EXCHANGE}

Higher consumption of alkaline chemicals is a major problem associated with alkaline flooding. This is due to adsorption, precipitation and reaction with rock minerals and formation water which leads to the loss of alkalis and create several undesirable effects including delayed breakthrough of alkalis. Therefore, to compensate the alkali consumption during flow through reservoir rock, higher concentration of alkaliis required to be injected.

The phenomenon of precipitate formation and the associated problems are discussed only by few authors even though it is widely believed that the injected alkali will generate precipitates upon reacting with the divalent cations present with the formation water. Laboratory investigations conducted on unconsolidated sand packs using different alkalis confirmed that the precipitate formation and its entrainment in porous media can lead to loss of permeability and unusual decline of productivity in production wells (Gruesbeck et al., 1982). Cheng, studied the extent of precipitation of different alkalis like $\mathrm{NaOH}, \mathrm{Na}_{2} \mathrm{CO}_{3}$ and $\mathrm{Na}_{4} \mathrm{SiO}_{4}$ on sand pack, initially saturated with $500 \mathrm{ppm}$ of $\mathrm{Ca}$ and $\mathrm{Mg}$ solutions. The pressure drop observed during the flooding of different alkalis was plotted against the pore volume injected. The highest pressure drop was recorded with $\mathrm{Na}_{4} \mathrm{SiO}_{4}$ and least with $\mathrm{Na}_{2} \mathrm{CO}_{3}$. Since no significant insoluble materials were found in the produced brine, it was confirmed that the increase in pressure drop is due to the permeability reduction which aroused due to the precipitate formation and entrainment. The precipitates of $\mathrm{Na}_{2} \mathrm{CO}_{3}$ are comparatively granular in size and therefore it cause less plugging effects and less pressure drop. Whereas, the precipitates of $\mathrm{NaOH}$ 
and $\mathrm{Na}_{4} \mathrm{SiO}_{4}$ are hydrated flocs and extremely plugging type and hence higher pressure drop was recorded during the flooding process (Cheng K.H, 1986). Alkaline flooding in a heterogeneous reservoir can cause precipitation of various insoluble salts within the formation faster than homogeneous reservoir. The variations in permeability and mobility can cause channeling or fingering of the injected alkali solution and sudden mixing with the formation brine of different composition and $\mathrm{pH}$ near the production well can cause incompatibility scale deposition (Katsanis et al., 1983). This is reported by Krumrine et al., (1985) in an alkaline field pilot in California. After analyzing the scale formed in the producing well, they found that the scales were made up of different precipitates like calcium carbonate, amorphous silica and magnesium silicate, which were later suppressed by squeezing scale inhibitors. In North Ward-Estes Field, Texas, incremental oil recovery was observed on $\mathrm{NaOH}$ flood at the initial stage. However soon production decline was observed and some of the wells were completely plugged by calcium sulfates. The near wellbore formation was plugged so badly that it was necessary to re-perforate the producing zones for scale inhibitor squeeze. The plugging materials were found to be by calcium sulfate, generated through the process of gypsum dissolution by alkaline slug (Raimondi et al., 1977).

Ion exchange is another major cause for alkali consumption during alkaline flooding and will result in longer alkali breakthrough and less than expected oil recovery efficiency. The exchange of ions happens between the multi-valent cations like $\mathrm{Ca}^{2+}, \mathrm{Ba}^{2+}$ and $\mathrm{Mg}^{2+}$ that are naturally present in the reservoir rock and brine, when they comes in contact with other ions present in the alkaline solutions being injected. During alkaline flooding, exchange of di-valent ions in the reservoir fluids with monovalent ions in the injected fluids will occur, which can delay the alkali breakthrough. Therefore, in order to avoid the contact between the hard water and alkaline solutions, a pre flush, usually soft water is injected (Katsanis et al., 1983). Another ion action takes place when alkalis are injected, which is the exchange of $\mathrm{Na}^{+}$with $\mathrm{H}^{+}$ions present in the rock surface to form water molecules. This exchange will also influence the $\mathrm{pH}$ of the slug front and reduce the alkali breakthrough at the production well. Experimental work by Cheng (1986) reported that in order to account for the alkali loss more amount of alkali must be added to the injected solution. Increasing the alkaline concentration will in turn increase the $\mathrm{pH}$ of the solution. And increasing the $\mathrm{pH}$ from 11 to 13 will cause an increase in the ion exchange in the tune of two or three folds. However, it was also reported that the use of $\mathrm{Na}_{2} \mathrm{CO}_{3}$ is advantageous compared to other alkalis, since its solution has the capacity to maintain low $\mathrm{pH}$ even when the total alkaline concentration is increased considerably and hence reduces the ion exchange potential to a great extent (Cheng K.H, 1986).

Another important reason for alkali loss is mineral dissolution. Mineral dissolution will occur when the injected alkali reacts with the rock formation and releasing ionic species into the brine. The rate of mineral dissolution increases with increase in pressure and temperature and the residence time of the alkaline solutions in the reservoir (Katsanis et al., 1983 and Cheng K.H, 1986). Experimental studies proved that mineral dissolution of silica was reduced considerably when $\mathrm{Na}_{2} \mathrm{CO}_{3}$ was used as alkali as compared to when $\mathrm{NaOH}$ and $\mathrm{Na}_{4} \mathrm{SiO}_{4}$ were used (Cheng K.H, 1986). In contrast to the negative effect of mineral dissolution, Sydansk, reported that, the dissolution of silica in sodium hydroxide solution which was injected to a sandstone core at high temperature $\left(185^{\circ} \mathrm{F}\right)$ resulted in increasing the porosity and finally improved oil recovery (Sydansk, R. D, 1982). However, this was one rare condition and mineral dissolution in most cases led to increase in alkali consumption.

\section{Combination Flooding}

\subsection{Alkali-Polymer (AP) flood}

Alkaline flooding and its various combinations are widely applied in the industry. One such variation is polymer augmented alkaline flooding, in which a polymer slug is injected after alkaline solutions. Alkaline-Polymer flooding is more efficient than injecting alkali or polymer alone. This is because the injected alkalis will help to mobilize the residual oil and the polymers helps to maintain a good mobility control and enhance the displacement efficiency (Mihcakan et al., 1986 and Burk, J. H. 1987). Laboratory experiments conducted on sandstone core plugs using polymer augmented alkaline $\left(\mathrm{NaOH}, \mathrm{Na}_{2} \mathrm{CO}_{3}\right.$ and $\mathrm{Na}_{4} \mathrm{SiO}_{4}$ ) flooding provided significantly high oil recovery (73\% to $95 \%$ ) than injecting polymers or alkalis alone, which resulted an oil recovery of $6 \%$ to $18 \%$ (Burk, J. H. 1987). Field tests of polymer augmented alkaline flooding also showed promising results. One such successful field test is the Isehour Unit in Wyoming which showed considerable increase in oil recovery when polymer augmented alkaline flooding was used (Doll, T. E. 1988). Another successful 
AP field test is from David Pool, Lloydminster Alberta which recovered 21.1\% of OOIP additionally after water flooding (Pitts et al., 2004). Chemical cost per incremental barrel produced was less than $\$ 1 /$ barrel making it very economic.

\subsection{Alkali-Surfactant (AS) flood}

This variation of alkaline flooding incorporates the addition of surfactants to reduce the IFT at oilwater interface to a greater extent than by using alkalis alone. In addition to the IFT reduction, emulsion formation is an added advantage of this process. Generated emulsion in-situ helps in improving the sweep efficiency by plugging the larger pores and redirecting the flow to new paths. Reduction in IFT and incremental oil recovery was obtained with AS flood in bera sandstone core plugs. Sodium carbonate was the alkali and Neodol $253 \mathrm{~S}$ was the surfactant used in this study (Taylor et al., 1990). and Increased heavy oil recovery from sand pack cores was achieved when AS slug was used and it was attributed to the improved sweep efficiency and reduction in IFT at oil-water interface (Bryan and Kantzas, 2007; Liu et al., 2007; Bryan et al., 2008). AS flood is more applicable in tight cores since it can generate emulsion in situ and enhance the sweep efficiency which otherwise can be achieved only with the addition of polymers. Laboratory study conducted on carbonate core plugs having low permeability reported considerable increase in recovery of water flood residual oil by using AS flood. Combine recovery from water flooding and AS flooding was $95 \%$ of OOIP (Mohan, K. 2009). Core flood tests performed on sand pack cores recovered $19.4 \%$ of OOIP during tertiary recovery with AS slug. Sodium carbonate and petroleum sulfonate were the alkali and surfactant used respectively in this study (Chen et al., 2013).

\subsection{Alkaline Surfactant Polymer (ASP)}

This is another major and widely used process variation of alkaline flooding. ASP flooding can increase the oil recovery considerably because of the synergy of its components like alkalis, surfactants and polymers in the slug being injected. ASP slug has alkalis which generate in-situ surfactants upon reacting with organic acids present in the crude oil, surfactants that reduce the IFT between oil and water and polymers which maintains a good mobility control of the injected solutions and increases the volumetric displacement efficiency. Laboratory tests on sandstone cores from West Keihl Unit, Wyoming using different alkalis, polymers and surfactants show that improved oil recovery from ASP flood was much higher than alkaline or polymer flooding alone. Recovery was $8.3 \%$ and $23 \%$ of OOIP beyond the water flood residual for polymer flooding and ASP flooding respectively. Since the ASP flooding shows significant improved oil recovery it was chosen and applied to the field (Clark et al., 1993).Vargo et al., 2000 reported a successful implementation of ASP flood in Cambridge Mennilusa field. ASP flood recovered 1,143,000 bbl of oil at a low cost of $\$ 2.42 / \mathrm{bbl}$. The recovered oil from ASP flood accounts for $28.1 \%$ of OOIP.

\section{The Alkali-Co-Surfactant Flood}

Another process variation of alkaline flooding is co-surfactant enhanced alkaline flooding. The efficiency of alkaline flooding is enhanced when a co-surfactant is added to the alkaline flood water (Nelson et al., 1984). During alkaline flooding, lowest IFT is produced when the alkali concentration is relatively low. The interactions between the fluids and rocks in the reservoir will lead to the loss of alkali and in order to maintain the required alkali concentration as a good effective slug, the alkali concentration is generally increased. However, increasing the alkali concentration increases the economics of the project. Therefore, in order to maintain good displacement efficiency by lowering the IFT and to get good displacement rate, some co-surfactants are added to the injected slug. This was proved by Nelson and his co-workers in 1984 by conducting laboratory tests on Berea sandstone core plug. They reported an increase in oil recovery when injecting a slug containing alkaline chemicals and a co-surfactant. The co-surfactant used was alcohol ethoxy-sulfate and olefin sulfonates (Nelson et al., 1984). First field test of co-surfactant enhanced alkaline flooding was conducted in White Castle Field, Louisiana in 1994. This field test reported $38 \%$ additional oil recovery from the water flood residuals (Falls et al., 1994).

\section{Alkaline Flooding in Carbonates}

First ASP flood laboratory test in carbonates was reported by Olsen et al in 1990. Recovery studies were conducted on carbonate cores using ASP, alkaline polymer and polymer slugs. The highest oil recovery beyond the water flood residual was observed for ASP flooding (45.3\%). 
The alkaline-polymer and polymer flooding recovered $10 \%$ and $11.3 \%$ of the residual oil after water flooding respectively (Olsen et al., 1990). Laboratory studies were performed to identify the potential of ASP flood for recovering residual oil from carbonate cores (Al-Hashim et al., 1996). Their study concluded that, ASP slug should be prepared with softened brine to protect it from the pre flush brines and combination of alkalis like sodium carbonate and sodium bicarbonate has the potential to reduce the adsorption of surfactants during flooding. Wettability of oil on calcite plate was altered from intermediate wet to a water wet state by using an alkaline surfactant system indicating the potential of AS slug for recovering residual oil from carbonates (Zhang et al., 2006). Bortolotti et al., (2009) studied the effect of intermittent alkali flooding on oil-wet carbonate cores and established that it can significantly enhance the oil recovery. The mechanisms are based on in-situ IFT reduction between the fluids and changing the wettability towards more water-wet state. Wettability alteration takes longer time to achieve and hence one week intermittent alkali flooding provides sufficient time for the alkalis to react to the rock surface and create wettability reversal. Strong alkali like $\mathrm{NaOH}$ is recommended for intermittent alkali flooding since high alkali concentration can create plugging of pore throats due to the precipitation and low alkali concentration will cause fast alkali consumption with time. Levitt et al., 2011, designed an ASP flood for high temperature, high salinity and low permeability carbonate cores. In this study, ASP slug containing $0.9 \mathrm{wt} \%$ surfactant, $2 \mathrm{wt} \%$ alkali and $0.35 \mathrm{wt} \%$ polymer was injected to the carbonate cores which recovered almost $91 \%$ of OOIP.

Many laboratory tests on ASP flood and field pilots were carried out at the initial stage of development in the early 1990s. Around 21 field pilots and large scale field projects of ASP flooding have been reported so far (Sheng et al., 2013). Most of the projects showed improved oil recovery but some problems like precipitation and scaling, difficulty in separating the produced emulsion, injectivity issues and degradation of the polymers were also seen in few field projects. Another laboratory test in 2013, reported incremental oil recovery of viscous oil form carbonate core (dolomite) using ASP flooding. In this test, the effect of ASP in recovering the residual oil in secondary and tertiary modes were studied. Water flooding recovered $47.8 \%$ followed by ASP which recovered another $44.9 \%$ making the total recovery to $97.2 \%$ of OOIP. On the other hand, when ASP flooding was done in the secondary stage, it recovered almost $95.6 \%$ of the original oil in place. These results confirmed that ASP flooding was more effective in the secondary mode (Panthi et al., 2013).A novel new approach of ASP flooding in carbonate reservoirs has been reported in 2014. A new approach of Acid Alkaline Surfactant Polymer flooding can overcome the precipitation effects in carbonates and it was reported by Kalwar and his co-workers in 2014. Their studies on carbonate cores revealed that using acrylic acid in ASP slug can minimize or avoid the precipitate formation of the di-valent cations present in the formation water. They also found out that ASP flood can increase the recovery of residual oil left in the carbonate reservoirs (Kalwar, et al., 2014a and 2014b).

One of the latest works on carbonates was reported by Kuwait Oil Company in 2015, where the effectiveness of ASP flooding in recovering residual oil from carbonate cores (predominantly limestone) was studied. The results were pleasing and the residual oil saturation was brought down to $6 \%$ in the laboratory. This led them to take this to the field and Single Well Tracer Test (SWTT) of ASP flooding was conducted and which established success of the technique. KOC planned to start an ASP pilot by 2017 in an inverted 5-spot pattern stretching across 6 acres (Abdullah et al., 2015). Comparisons between polymer, alkaline polymer, surfactant polymer and alkaline surfactant polymer flooding were performed on carbonated core plugs to find its potential for recovering residual oil. This study found out that, highest oil recovery is obtained with ASP flooding when compared with others. Different ASP floods recovered 82-89\% of OOIP whereas the other floods recovered only 69$71 \%$ of OOIP (Shedid, 2015). Additionally, application of ASP flooding in earlier stages recovered more oil than when applied to late stages after water flooding process.

\section{Conclusions}

Though the alkaline flooding and its different process variations are widely applied in sandstone reservoirs, its application in carbonate reservoirs are limited because of the great heterogeneity in carbonates and due to high presence of divalent cations that will react with the injected alkalis and creates precipitation and scaling problems. However, few researchers have published some works on carbonates and many are working on it for making it a promising EOR technique in carbonates. 


\section{ACKNOWLEDGEMENT}

Authors would like to thank The Petroleum Institute for giving the opportunity to do this study.

\section{NOMENCLATURE}

$\begin{array}{ll}\text { AP } & \text { - Alkaline Polymer } \\ \text { AS } & \text { - Alkaline Surfactant } \\ \text { ASP } & \text { - Alkaline Surfactant Polymer } \\ \text { EOR } & \text { - Enhanced Oil Recovery } \\ \text { IFT } & \text { - Interfacial Tension } \\ \text { OOIP } & \text { - Original Oil in Place } \\ \text { SWTT } & \text { - Single Well Tracer Test }\end{array}$

\section{REFERENCES}

[1] Abdullah, M., Tiwari, S., \& Pathak, A. (2015). Evolution of Chemical EOR (ASP) Program for a Carbonate Reservoir in North Kuwait. Paper SPE-172608 presented at the Middle East Oil \& Gas Show and Conference, Manama, Bahrain, 8-11 March.

[2] Al-Hashim, H.S., Obiora, V., Al-Yousef, H.Y., Fernandez, F., \& Nofal, W. (1996). Alkaline Surfactant Polymer Formulation for Saudi Arabian Carbonate Reservoirs. Paper SPE-35353 presented at the SPE/DOE Improved Oil Recovery Symposium, Tulsa, Oklahoma, 21-24 April.

[3] Atkinson, H. (1977): "Recoveryof Petroleum from Oil Bearing Sands", U.S. Patent No.1651311

[4] Bortolotti, V., Gottardi, G., Macini, P., \& Srisuriyachai, F. (2009). Intermittent Alkali Flooding in Vertical Carbonate Reservoirs. Paper SPE-121832-MS. Presented at EUROPEC/EAGE Conference and Exhibition, Amsterdam, The Netherlands, 8-11 June.

[5] Bryan, J. L., \& Kantzas, A. (2007). Enhanced Heavy-Oil Recovery by Alkali-Surfactant Flooding. Paper SPE-110738 presented at the Annual Technical Conference and Exhibition, Anaheim, California, U.S.A, 11-14 November.

[6] Bryan, J. L., Mai, A. T., \& Kantzas, A. (2008). Investigation into the Processes Responsible for Heavy Oil Recovery by Alkali-Surfactant Flooding. Paper SPE-113993 presented at the SPE Symposium on Improved Oil Recovery, Tulsa, Oklahoma, 20-23 April.

[7] Burk, J. H. (1987). Comparison of Sodium Carbonate, Sodium Hydroxide, and Sodium Orthosilicate for EOR. SPE Reservoir Engineering, Vol 2, Issue 01: p.p. 9-16.

[8] Campbell, T.C.(1982). The Role of Alkaline Chemicals in the Recovery of Low-Gravity Crude Oils. Journal of Petroleum Technology, Vol 34, Issue 11 p.p. 2,510-2,516.

[9] Chen, L., Zhang, G., Ge, J., Jiang, P., \& Liu, Y. (2013).Research of the heavy oil displacement mechanism by using alkaline/surfactant flooding system. Journal of Colloids and Surfaces A: Physicochemical and Engineering Aspects. Volume 434, Pages 63-71

[10] Cheng, K. H. (1986). Chemical Consumption during Alkaline Flooding: A Comparative Evaluation. Paper SPE-14944 presented at the SPE Enhanced Oil Recovery Symposium, Tulsa, Oklahoma, 20-23 April.

[11] Clark, S. R., Pitts, M. J., \& Smith, S. M. (1993). Design and Application of an AlkalineSurfactant-Polymer Recovery System to the West Kiehl Field. SPE Advanced Technology Series, Vol 1, Issue 1: p.p. 172-179.

[12] Cooke Jr, C., Williams, R. and Kolodzie, P. (1974). Oil Recovery by Alkaline Waterflooding. Journal of petroleum technology, 26(12): p.p. 1,365-1,374.

[13] DeZabala, E., Vislocky, J., Rubin, E. and Radke, C.(1982). A chemical Theory for Linear Alkaline Flooding. Society of Petroleum Engineers Journal, 22(02): p.p. 245-258.

[14] Doll, T. E. (1988). Performance Data Through 1987 of the Isenhour Unit, Sublette County, Wyoming, Polymer-Augmented Alkaline Flood. Paper SPE-17801 presented at the SPE Rocky Mountain Regional Meeting, Casper, Wyoming, 11-13 May.

[15] Doscher, T.M. (1956): “Oil Recovery From Tar Sands”, U.S. Patent No.3279538 
[16] Ehrlich, R., Hasiba, H. H., \& Raimondi, P. (1974). Alkaline Water flooding for Wettability Alteration-Evaluating a Potential Field Application. Journal of Petroleum Technology, Vol 26, Issue 12, p.p. 1,335-1,343.

[17] Falls, A. H., Thigpen, D. R., Nelson, R. C., Ciaston, J. W., Lawson, J. B., Good, P. A, Ueber, R. C., \&Shahin, G. T. (1994). Field Test of Co surfactant-Enhanced Alkaline Flooding. Journal SPE Reservoir Engineering. Volume 9, Issue 03.

[18] Gruesbeck, C., \& Collins, R. E. (1982). Entrainment and Deposition of Fine Particles in Porous Media. Society of Petroleum Engineers Journal, Vol 22, Issue 06: p.p. 847-856.

[19] Jennings, H. Y., Johnson, C. E., \& McAuliffe, C. D. (1974). A Caustic Water flooding Process for Heavy Oils. Journal of Petroleum Technology, Vol 26, Issue 12, p.p. 1,344-1,352.

[20] Johnson, C. E. (1976). Status of Caustic and Emulsion Methods. Society of Petroleum Engineers. Journal of Petroleum Technology, Vol 28, Issue 01, p.p. 85-92.

[21] Kalwar, S.A., Elraies, K.A., Kumar, S. \& Abbas, G. (2014). Wettability Alteration by New AcidAlkali-Surfactant-Polymer Formulation in High Salinity Carbonate Reservoirs. Paper OTC24738-MS. Offshore Technology Conference-Asia, Kuala Lumpur, Malaysia, 25 - 28 March.

[22] Kalwar, S. A., Elraies, K. A., Memon, M. K., Kumar, S., Abbas, G., \& Mithani, A. H. (2014). A New Approach to ASP Flooding in High Saline and Hard Carbonate Reservoirs. Paper SPE17809 presented at the International Petroleum Technology Conference, Kuala Lumpur, Malaysia, 10-12 December.

[23] Katsanis, E. P., Krumrine, P. H., \& Falcone, J. S. (1983). Chemistry of Precipitation and Scale Formation in Geological Systems. Paper SPE-11802 presented at the SPE Oilfield and Geothermal Chemistry Symposium, Denver, Colorado, 1-3 June.

[24] Krumrine, P. H., Mayer, E. H., \& Brock, G. F. (1985). Scale Formation during Alkaline Flooding. Journal of Petroleum Technology, Vol 37, Issue 08, p.p. 1,466-1,474.

[25] Leach, R., Wagner, O., Wood, H. \& Harpke, C. (1962). A Laboratory and Field Study of Wettability Adjustment in Water flooding. Journal of Petroleum Technology, Vol 14, Issue 02: p.p. 206-212.

[26] Levitt, D., Dufour, S., Pope, G. A., Morel, A. C., \& Gauer, P. R. (2011). Design of an ASP flood in a High-Temperature, High-Salinity, Low-Permeability Carbonate. Paper SPE-14915 presented at the International Petroleum Technology Conference, Bangkok, Thailand, 15-17 November.

[27] Liu, Q., Dong, M., Ma, S., \&Tu, Y. (2007).Surfactant enhanced alkaline flooding for Western Canadian heavy oil recovery. Journal of Colloids and Surfaces A: Physicochemical and Engineering Aspects. Volume 293, Issues 1-3,Pages 63-71

[28] Mayer, E., Berg, R., Carmichael, J., \&Weinbrandt, R.(1983). Alkaline Injection for Enhanced Oil Recovery-A Status Report. Journal of Petroleum Technology, Vol 35, Issue 01: p.p. 209-221.

[29] Mihcakan, I. M., \& Van Kirk, C. W. (1986). Blending Alkaline and Polymer Solutions Together Into a Single Slug Improves EOR. Paper SPE-15158 presented at the SPE Rocky Mountain Regional Meeting, Billings, Montana, 19-21 May.

[30] Mohan, K. (2009). Alkaline Surfactant Flooding for Tight Carbonate Reservoirs. Paper SPE129516 presented at the SPE Annual Technical Conference and Exhibition, New Orleans, Louisiana, 4-7 October.

[31] Mungan, N. (1966). Interfacial Effects in Immiscible Liquid-Liquid Displacement in Porous Media. Society of Petroleum Engineers Journal, Vol 6, Issue 03: p.p. 247-253.

[32] Nelson, R., Lawson, J., Thigpen, D., \&Stegemeier, G. (1984). Cosurfactant-Enhanced Alkaline Flooding. Paper SPE-12672 presented at the SPE Enhanced Oil Recovery Symposium, Tulsa, Oklahoma, 15-18 April.

[33] Olsen, D., Hicks, M., Hurd, B., Sinnokrot, A., \&Sweigart, C. (1990). Design of a Novel Flooding System for an Oil-Wet Central Texas Carbonate Reservoir. Paper SPE-20224-MS. SPE/DOE Enhanced Oil Recovery Symposium, Tulsa, Oklahoma, 22 - 24 April.

[34] Panthi, K. K., Sharma, H., \&Mohanty, K. K. (2013). ASP Flood of a Viscous Oil in a Carbonate Rock. Paper SPE-166230 presented at the SPE Annual Technical Conference and Exhibition, New Orleans, Louisiana, USA, 30 September-2 October. 
[35] Panthi, K., Sharma, H., \&Mohanty, K.K. (2016). ASP flood of a viscous oil in a carbonate rock. Fuel, 164: p.p. 18-27.

[36] Pitts, M. J., Wyatt, K., \&Surkalo, H.(2004). Alkaline-Polymer Flooding of the David Pool, Lloydminster Alberta. Paper SPE-89386 presented at the SPE/DOE Symposium on Improved Oil Recovery, Tulsa, Oklahoma,17-21 April.

[37] PQ Corporation (2006). Silicates in Enhanced Oil Recovery, Bulletin 35-04

[38] Raimondi, P., Gallagher, B., Ehrlich, R., Messmer, J., \& Bennett, G. (1977). Alkaline Waterflooding: Design and Implementation of a Field Pilot. Journal of Petroleum Technology, Vol 29, Issue 10, p.p. 1,359-1,368.

[39] Shedid, S. A. (2015). Experimental Investigation of Alkaline/Surfactant/Polymer (ASP) Flooding in Low Permeability Heterogeneous Carbonate Reservoirs. Paper SPE-175726 presented at the SPE North Africa Technical Conference and Exhibition, Cairo, Egypt, 14-16 September.

[40] Sheng, J.J. (2014). A Comprehensive Review of Alkaline-Surfactant-Polymer (ASP) Flooding. Asia-Pacific Journal of Chemical Engineering, 9(4): p.p. 471-489.

[41] Subkow, P. (1942): "Process for the Removal of Bitumen from Bituminous Deposits," U.S. Patent No. 2288857

[42] Surkalo, H. (1990). Enhanced Alkaline Flooding. Journal of petroleum technology, 42(01): p.p. 6-7.

[43] Squires, F (1917): "Method of Recovering Oil and Gas", U.S. Patent No.1238355

[44] Sydansk, R. D. (1982). Elevated-Temperature Caustic/Sandstone Interaction: Implications for Improving Oil Recovery (includes associated papers 11348 and 11548). Society of Petroleum Engineers Journal, Vol 22, Issue 04: p.p. 453-462

[45] Taylor, K. C., Hawkins, B. F., \& Islam, M. R. (1990). Dynamic Interfacial Tension In Surfactant Enhanced Alkaline Flooding. Journal of Canadian Petroleum Technology.Volume29, Issue01.

[46] Vargo, J., Turner, J., Bob, V., Pitts, M. J., Wyatt, K., Surkalo, H., \& Patterson, D. (2000). Alkaline-Surfactant-Polymer Flooding of the Cambridge Minnelusa Field. Journal SPE Reservoir Evaluation \& Engineering.Volume14, Issue06.

[47] Wagner, O. R., \& Leach, R. O. (1959). Improving Oil Displacement Efficiency by Wettability Adjustment. Transactions of the AIME, Vol 216, Issue 01: p.p. 65-72.

[48] Zhang, D. L., Liu, S., Puerto, M., Miller, C. A., \& Hirasaki, G.J. (2006). Wettability alteration and spontaneous imbibition in oil-wet carbonate formations. Journal of Petroleum Science and Engineering. Volume 52, Issues Pages 213-226. 